\title{
Role of the different chemical components in the conditioning process of air exposed copper surfaces
}

\author{
V. Petit, ${ }^{1,2,}$ M. Taborelli, ${ }^{1}$ H. Neupert, ${ }^{1}$ P. Chiggiato, ${ }^{1}$ and M. Belhaj ${ }^{2}$ \\ ${ }^{1}$ European Organization for Nuclear Research, CERN, 1211, Geneva 23, Switzerland \\ ${ }^{2}$ ONERA The French Aerospace Lab, 31055 Toulouse, France
}

(Received 12 November 2018; published 9 August 2019)

\begin{abstract}
As a source of heat load on cryogenic sections, the electron cloud is currently a major limitation to the intensity of some modern particle accelerators such as the LHC and its high luminosity upgrade at CERN. During LHC operation, conditioning of the copper beam pipe surface occurs, leading to a decrease of the cloud intensity. To understand the role of the different chemical surface components of air exposed copper in the electron conditioning process, air exposed copper samples as well as specific model surfaces produced in the laboratory, namely sputter-cleaned copper and carbon-free cuprous oxide $\left(\mathrm{Cu}_{2} \mathrm{O}\right)$, were conditioned by low energy electron irradiation. Conditioning of air exposed copper results in a decrease of the maximum secondary electron yield (SEY) below 1.1. Surface cleaning by electron stimulated desorption and carbon graphitization without increase of the carbon surface concentration are observed by $\mathrm{x}$-ray photoelectron spectroscopy. After conditioning, the maximum SEY of both sputter-cleaned copper and $\mathrm{Cu}_{2} \mathrm{O}$ remains higher than 1.1. No significant surface modification is observed by $\mathrm{x}$-ray photoelectron spectroscopy during irradiation for these two surfaces. These results prove that neither an increase of the amount of surface carbon nor oxide modification is responsible for the SEY reduction observed during electron irradiation of air exposed copper. They confirm that graphitic carbon is required to decrease the maximum SEY of copper below 1.1.
\end{abstract}

DOI: 10.1103/PhysRevAccelBeams.22.083101

\section{INTRODUCTION}

During the operation of particle accelerators with high intensity and positively charged beams, primary electrons are generated in the beam vacuum pipe by both residual gas ionization and photoemission induced by synchrotron radiation hitting the chamber wall. Then, a cascade phenomenon follows, the so-called electron multipacting, involving the acceleration of primary electrons by the beam potential, their collision with the chamber wall and the emission of secondary electrons, leading to the buildup of an electron cloud inside the beam vacuum chamber. Electron multipacting in particle accelerators is responsible for beam losses and instabilities [1] as well as vacuum degradation [2-4]. Furthermore, as a source of heat load on cryogenic systems, the electron cloud is currently one of the main limitations to the beam intensity of the LHC and its future upgrade, the high luminosity LHC [5-8].

\footnotetext{
valentine.petit@cern.ch

Published by the American Physical Society under the terms of the Creative Commons Attribution 4.0 International license. Further distribution of this work must maintain attribution to the author(s) and the published article's title, journal citation, and DOI.
}

The secondary electron yield (SEY) of the inner surface of the beam pipe governs the multiplication of impinging electrons and sets the threshold of beam charge and structure for the occurrence of the electron cloud. Several mitigation techniques have been developed to get rid of the electron cloud, including laser engineering of the beam pipe inner surface [9], solenoids wound around the vacuum chamber [10], clearing electrodes [11] and lowSEY carbon coatings [12]. Fortunately, for several materials used in the vacuum system of particle accelerators, in particular copper, the SEY decreases along the accelerator operation time, lowering the cloud intensity. Some modern particle accelerators partly rely on this effect [13-15] referred to as conditioning or beam scrubbing to lower the SEY of the beam pipe and to control the effects of the electron cloud.

The maximum SEY of an air exposed copper surface is about 2.0 [16,17]. When bombarded by electrons with energies higher than $50 \mathrm{eV}$, the SEY of such a surface is observed to decrease and reaches a saturation value of about 1.1 [18] at a dose of $10^{-2} \mathrm{C} / \mathrm{mm}^{2}$.

The surface of an air exposed copper plate is formed by several chemical components. The air formed layer consists of a $\mathrm{Cu}_{2} \mathrm{O}$ layer reported in the literature to be about $1.5 \mathrm{~nm}$ thick $[19,20]$ and a thinner topmost layer containing hydrocarbons, hydroxyl species and water [19,20]. 
Several surface modifications occur during electron irradiation, which might be responsible for the corresponding SEY decrease. Indeed, both surface cleaning by electron stimulated desorption (ESD) $[21,22]$ and graphitization of the adventitious carbon layer $[17,18,23,24]$ were observed. Furthermore, an increase of carbon amount on the surface was sometimes reported [17,23-25] and found to be necessary to decrease the maximum SEY of copper to about 1.1 by some authors [24]. Nonetheless, other mechanisms such as oxide modification upon irradiation have to be considered.

The aim of this work is to investigate and disentangle the role of each chemical surface component in the conditioning process of an air exposed copper surface. For this purpose, model surfaces were produced and studied: sputter-cleaned copper, carbon-free cuprous oxide $\left(\mathrm{Cu}_{2} \mathrm{O}\right)$ and air exposed copper samples have been conditioned and the ultimate maximum SEY together with the induced surface modifications are reported and compared.

\section{EXPERIMENTAL}

\section{A. Experimental setup}

The experiments were carried out at room temperature in a baked UHV system (base pressure $6 \times 10^{-10}$ mbar) made out of $\mu$-metal. The setup is equipped for $\mathrm{x}$-ray photoelectron spectroscopy (XPS) analysis at normal emission angle (monochromatic $\mathrm{Al} \mathrm{K} \alpha$ source, $\mathrm{h} \nu=1486.7 \mathrm{eV}$ ) and SEY measurement. An electron flood gun allows sample irradiation for the conditioning study and an $\mathrm{Ar}^{+}$ion gun is available for in situ cleaning of the samples and oxide thickness measurements by XPS sputter depth profiling (erosion speed calibrated for $\mathrm{Ta}_{2} \mathrm{O}_{5}$ ). An insertion chamber (load lock), pumped by a turbomolecular pump (base pressure $2 \times 10^{-8} \mathrm{mbar}$ ) was used for inserting and oxidizing samples in a controlled atmosphere. The atomic percentages for the surface concentrations of the elements are calculated from the respective peak areas of the XPS spectra weighted with the respective sensitivity factors. We estimated an error of 0.2 at. \% on the low carbon content samples, based on the instrumental carbon detection limit.

\section{B. SEY measurement}

The SEY $\delta$ is defined as the ratio of the total number of emitted (true secondary and backscattered) electrons $I_{s}$ to the number of impinging electrons $\mathrm{I}_{p}$. SEY measurements were carried out at normal incidence, between 0 and $1800 \mathrm{eV}$ electron landing energy. The primary current $\mathrm{I}_{p}$ was first measured applying a positive bias on the sample $\left(\mathrm{V}_{\mathrm{sa}}=+45 \mathrm{~V}\right)$. The bias was then switched to negative value $\left(\mathrm{V}_{\mathrm{sa}}=-45 \mathrm{~V}\right)$ and the sample current $\mathrm{I}_{\mathrm{sa}}=\mathrm{I}_{p}-\mathrm{I}_{s}$ was measured. The SEY is then computed: $\delta=1-\mathrm{I}_{\mathrm{sa}} / \mathrm{I}_{p}$. The fact that the system does not use a Faraday cup for the measurement of $\mathrm{I}_{p}$ induces an error on the absolute value of $\delta$, since some elastically scattered electrons can escape from the positively biased sample, thus leading to a slight underestimation of $\mathrm{I}_{p}$. A comparison on sputter-cleaned copper between literature curves where measurements were performed with a Faraday cup [16] and curves presented here below (see Sec. III B), shows that this error is negligible on the entire considered energy range, and is in particular below 0.1 on the absolute maximum SEY $\left(\delta_{\max }\right)$. The error on the values of $\delta_{\max }$ generated by the error on the measured currents is at maximum \pm 0.005 for all the data presented below. For each sample state, the SEY was acquired on three different locations of the same sample, to assess its homogeneity. The associated scattering was at maximum 0.02 between the smallest and the highest $\delta_{\max }$ measured on the same sample and includes the error contribution from the current measurements. Considering all the sources of error/uncertainty previously mentioned we conclude that the error bars on $\delta_{\max }$ for this comparative study are \pm 0.01 . The primary current was kept below $2.5 \mathrm{nA}$ to limit the sample conditioning during the SEY measurement (estimated corresponding dose: $4 \times 10^{-7} \mathrm{C} / \mathrm{mm}^{2}$ ). The energy scale of the SEY curves is referenced to the Fermi level of the sample. The work function $\phi$ is taken as the energy difference between Fermi and the vacuum levels, as defined in [26]. The work function was extracted from the low primary energy part of the SEY curve. The adopted method, called beam-stop method, was already applied $[26,27]$ and is correct when the beam is impinging normally to the surface. The value of the work function was chosen as being at the inflexion point of the SEY drop corresponding to the transition from fully backscattered beam $(\delta=1)$ to partly absorbed beam $(\delta<1)$. This procedure is in principle exact for a Gaussian energy beam profile and a sharp step function as a surface potential. The accuracy of this method is experimentally estimated to be $\pm 0.1 \mathrm{eV}$. A sputter-cleaned gold sample $(\phi=5.3 \mathrm{eV}$ [28]) was used for the calibration of the energy scale of the SEY curves.

\section{Sample preparation}

The samples were $10 \times 10 \times 1 \mathrm{~mm}^{3}$ pieces cut from a polycrystalline oxygen-free copper (C 10100) sheet. All samples were either predegreased in hexane and dipped for $2 \mathrm{~h}$ in an ultrasonic bath of ethanol or wet cleaned in a commercial detergent, as specified later for each sample. The sample state after any of these cleaning procedures is referred to as "as received." "Sputter-cleaned" samples were obtained by in situ $\mathrm{Ar}^{+}$sputtering at $3 \mathrm{keV}$ of the full sample surface (after detergent cleaning), until only copper and traces of argon could be detected by XPS. Carbon-free oxidized samples were obtained from two different processes to obtain a thin and a thicker oxide layer. In the first process, sputter-cleaned samples were transferred to the load lock chamber, where they were vented to atmospheric pressure with a mixture of $\mathrm{N}_{2}\left(80 \mathrm{~mol} \%\right.$, purity 55) and $\mathrm{O}_{2}$ (20 mol \%, purity 60) for 45 minutes. After the evacuation of the load lock, the samples were transferred back to the 

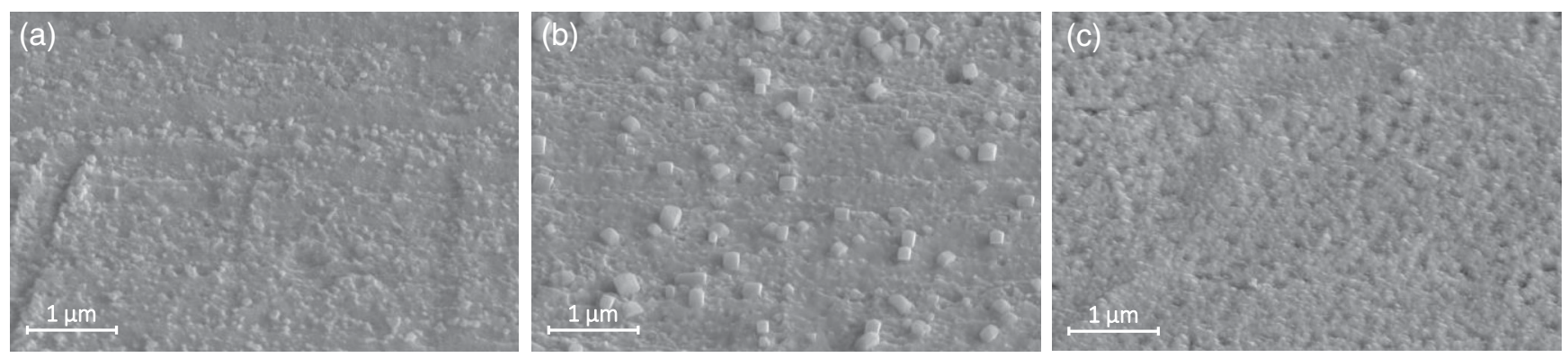

FIG. 1. Scanning electron microscopic images of (a) as received sample after hexane and ethanol cleaning, (b) load lock oxide sample after 1 day in air and (c) thick oxide sample. The pictures were taken with the electron beam impinging on the sample at 45 degres with respect to the surface normal to enhance contrast.

analysis chamber. These samples are referenced as "load lock" samples. In the second process, an as received sample (after detergent cleaning) was oxidized for $270 \mathrm{~h}$ at $120^{\circ} \mathrm{C}$ in air, changing the sample surface color to blue. Afterwards, this thick oxide sample was introduced in the UHV system where it was shortly sputtered to remove carbon contamination. This sputtering step is not expected to significantly modify the oxide stoichiometry [29]. However, the production of defects within the oxide layer cannot be excluded. The oxide thickness of these two kinds of samples was measured by depth profiling in the XPS system by $\mathrm{Ar}^{+}$sputtering and were found to be 1.9 and $55 \mathrm{~nm}\left(\mathrm{Ta}_{2} \mathrm{O}_{5}\right.$ equivalent) for load lock and thick oxide samples respectively. These values are in agreement with expectations from literature [30-32].

The surface morphology of these samples was observed by scanning electron microscopy and the corresponding images are given in Fig. 1 together with observation performed on an as received (hexane and ethanol cleaned) sample. The surface of the as received sample exhibits damages such as striae characteristic for a laminated material. Scattered cubic surface features of a few hundredth of nanometers on the surface of the load lock sample are compatible with the cubic crystallographic structure of cuprous oxide. The surface of the thick oxide sample appears rougher and more porous than the two other samples, possibly as a result of the oxidation procedure.

Conditioning was carried out using a flood gun at $\mathrm{E}=$ $250 \mathrm{eV}$ at normal incidence. The sample current during irradiation was about $150 \mu \mathrm{A}$ (measured with $\mathrm{V}_{\mathrm{sa}}=+20 \mathrm{~V}$ ) for an irradiated area estimated to $1000 \mathrm{~mm}^{2}$. For all samples, the irradiation was performed up to an electron dose of $10^{-2} \mathrm{C} / \mathrm{mm}^{2}$, where the decrease of the maximum SEY of copper is known to saturate [18], corresponding to about $19 \mathrm{~h}$ of irradiation. The pressure typically increased from 6-7 $\times 10^{-10}$ mbar to about $2 \times 10^{-9}$ mbar when starting the irradiation, except for the as received sample where the pressure increased from $1 \times 10^{-9}$ mbar to $5 \times 10^{-9}$ mbar. The pressure at the end of the conditioning before stopping the flood gun was $1 \times 10^{-9}$ mbar for all the samples. During irradiation, a thermocouple fixed on the manipulator did not show any significant change of sample temperature. Previously to each experiment, the flood gun was extensively degassed and the sample holder and sample stage were baked at $250^{\circ} \mathrm{C}$ in UHV for $12 \mathrm{~h}$.

\section{RESULTS}

A summary of the surface atomic concentrations measured by XPS, electron emission parameters and work function is presented in Table I for all the samples and their corresponding states.

\section{A. As received sample}

After years of air exposure followed by wet cleaning procedure with hexane and ethanol, the surface of the as received sample exhibits an airborne contamination layer [20] containing carbon species up to 40.6 at. \%, oxygen, nitrogen and traces of calcium and chlorine below 1 at. \%. The core level spectra for carbon, oxygen and copper of the as received sample are shown in Fig. 2. $\mathrm{A} \mathrm{Cu}_{2} \mathrm{O}$ layer is identified by the position of the Cu LMM Auger line $\left(\mathrm{E}_{K}=916.4 \mathrm{eV}\right)$ [33]. The presence of hydroxide is deduced from the $\mathrm{Cu} 2 \mathrm{p}_{3 / 2}$ line at $\mathrm{E}_{b}=934.3 \mathrm{eV}$ [19,34], its associated satellite shape [34] and the position of the $\mathrm{O} 1 \mathrm{~s}$ line at $\mathrm{E}_{b}=531.5 \mathrm{eV}$ [35]. From the decrease of the $\mathrm{O} 1 \mathrm{~s}$ intensity in the XPS depth profile, the thickness of the oxide/hydroxide layer was measured to be $5.5 \mathrm{~nm}$ thick (equivalent $\mathrm{Ta}_{2} \mathrm{O}_{5}$ ).

Figure 3 shows that the maximum SEY of the as received sample yields at 2.00 for an energy $E_{\max }$ of $300 \mathrm{eV}$, in line with Refs. [16,17]. On the low energy part, the SEY goes down to a minimum of 0.25 just above the sample vacuum level. The yield increases then in two steps, separated by a plateau where $\delta=0.55$ between 8 and $16 \mathrm{eV}$ above Fermi level. The work function is $4.8 \mathrm{eV}$.

After full conditioning up to the saturation dose of $10^{-2} \mathrm{C} / \mathrm{mm}^{2}$, the maximum yield is decreased down to 1.07 and $\mathrm{E}_{\max }$ is about $300-350 \mathrm{eV}$. Even though the work function does not seem to be affected by irradiation $(\phi=4.9 \mathrm{eV})$, the electron yield just above the vacuum level is strongly decreased and the following increase is 
TABLE I. Summary of analyzed characteristics of all the samples and their different states: surface atomic concentrations of carbon, oxygen, nitrogen and copper determined by XPS, electron emission parameters $\left(\delta_{\max }\right.$ and $\left.\mathrm{E}_{\max }\right)$ and work function $\phi$.

\begin{tabular}{lcccccccr}
\hline \hline & \multicolumn{9}{c}{ Surface atomic concentration [at. \%] } & & \\
\cline { 2 - 5 } Sample name & $\mathrm{C}$ & $\mathrm{O}$ & $\mathrm{N}$ & $\mathrm{Cu}$ & Other & $\delta_{\max }$ & $\mathrm{E}_{\max }[\mathrm{eV}]$ & $\phi[\mathrm{eV}]$ \\
\hline As received & 40.6 & 32.0 & 1.9 & 24.3 & $1.2^{\mathrm{a}}$ & 2.00 & 300 & 4.8 \\
As received + conditioned & 36.8 & 12.5 & 2.7 & 45.3 & $2.7^{\mathrm{a}}$ & 1.07 & $300-350$ & 4.9 \\
Sputter cleaned & $\ldots$ & $\ldots$ & $\ldots$ & 99.3 & $0.7^{\mathrm{b}}$ & 1.44 & 700 & 4.3 \\
Sputter cleaned + conditioned & 1.6 & 0.6 & 0.3 & 97.1 & $0.5^{\mathrm{b}}$ & 1.32 & 600 & 4.7 \\
Sputter cleaned + vacuum stored & 1.1 & 0.2 & $\ldots$ & 98.4 & $0.3^{\mathrm{b}}$ & 1.40 & 700 & 4.6 \\
Load lock sample & 0.5 & 8.4 & 0.1 & 90.6 & $0.4^{\mathrm{b}}$ & 1.26 & 500 & 4.8 \\
Load lock + conditioned & 1.7 & 7.2 & 0.7 & 89.8 & $0.6^{\mathrm{b}}$ & 1.16 & 500 & 5.0 \\
Thick oxide sample & 0.2 & 15.3 & $\ldots$ & 83.3 & $1.3^{\mathrm{c}}$ & 1.25 & 500 & 4.9 \\
Thick oxide + conditioned & 2.0 & 14.8 & $\ldots$ & 82.1 & $1.1^{\mathrm{c}}$ & 1.18 & 400 \\
\hline \hline
\end{tabular}

${ }^{\mathrm{a}} \mathrm{Cl}$ and $\mathrm{Ca}$.

${ }^{\mathrm{b}} \mathrm{Ar}$.

${ }^{\mathrm{c}} \mathrm{Si}$ and $\mathrm{Ar}$.

smoother in comparison with the as received state. Strong surface modifications are observed by XPS as reported in Fig. 2. Surface cleaning and chemical modifications are observed through: the disappearance of the peak at
$288.5 \mathrm{eV}$ on the $\mathrm{C} 1 \mathrm{~s}$ line, ascribed to carboxyl groups [36]; the vanishing of the copper hydroxide contribution in the $\mathrm{Cu} 2 \mathrm{p}_{3 / 2}$ peak together with the shift of the $\mathrm{O} 1 \mathrm{~s}$ line to $\mathrm{E}_{b}=530.3 \mathrm{eV}$ (compatible with $\mathrm{Cu}_{2} \mathrm{O}$ [19]); and the
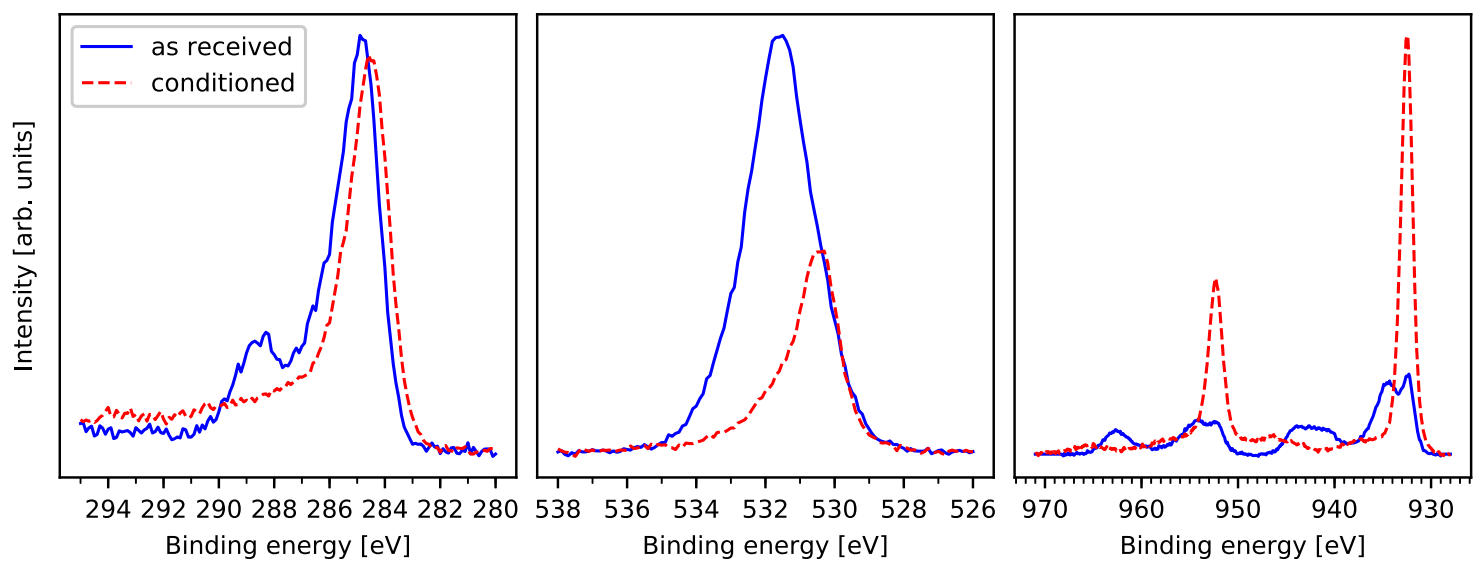

FIG. 2. $\mathrm{C} 1 \mathrm{~s}$ (left), $\mathrm{O} 1 \mathrm{~s}$ (center) and $\mathrm{Cu} 2 \mathrm{p}$ (right) lines of as received sample, before and after a full conditioning process.
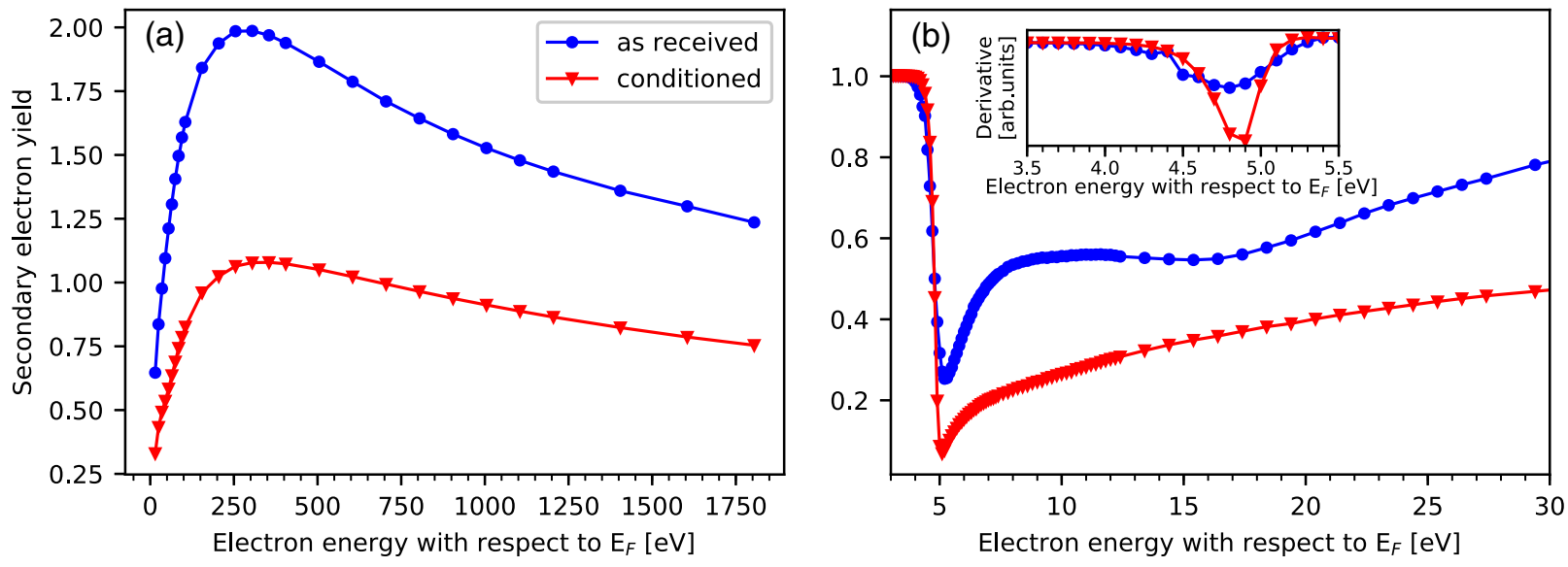

FIG. 3. (a) SEY curves from 10 to $1800 \mathrm{eV}$ of an as received sample, before and after full conditioning, (b) low energy SEY curves, inset: derivative of the SEY curves in the vacuum level region. 
decrease of the oxygen amount down to 12.5 at. \%. As a result, the area of the $\mathrm{O} 1 \mathrm{~s}$ peak decreases and the one below the $\mathrm{Cu} 2 \mathrm{p}$ line increases as clearly visible in Fig. 2. A slight decrease of the carbon surface concentration is also observed (Table I), in contrast to some of the previous works $[17,24,25]$. In addition, a shift of the $\mathrm{C} 1 \mathrm{~s}$ line to lower binding energy $\left(\mathrm{E}_{b}=284.6 \mathrm{eV}\right.$ instead of $284.9 \mathrm{eV}$ before conditioning) is clearly visible, demonstrating a graphitization of the adventitious carbon layer [37] in accordance with previous studies [17,18,23,24]. Part of these effects can be ascribed to electron stimulated desorption.

\section{B. Sputter-cleaned samples}

XPS spectra acquired on a sputter-cleaned sample and shown in Fig. 4 exhibit $\mathrm{Cu} 2 \mathrm{p}_{3 / 2}$ and $\mathrm{Cu}$ LMM Auger peaks at $\mathrm{E}_{b}=932.6 \mathrm{eV}$ and $\mathrm{E}_{k}=918.7 \mathrm{eV}$ respectively, as expected for the metallic copper state [20,33]. Apart from argon (implanted during ion bombardment), no other element was detected. The composition in terms of hydroxide and carbon concentrations of the sputter-cleaned sample in its as received state (before sputtering) was slightly different from the as received sample described above (Sec. III A, Figs. 2 and 3) due to the different cleaning procedures. However, in the present case, the as received state is used only as a reference for the $\mathrm{C} 1 \mathrm{~s}$ position of the airborne contamination which is the same as for the as received sample presented in Fig. 2.

The SEY curves for sputter-cleaned sample are given in Fig. 5. The maximum SEY of such samples was measured at $\delta_{\max }=1.44$ for $\mathrm{E}_{\max }=700 \mathrm{eV}$. The values and the curve shape are consistent with literature [16,17]. The work function was found to be between 4.2 and $4.4 \mathrm{eV}$ among several samples (4.3 eV for the sample shown in Figs. 4 and 5) in agreement with Ref. [28]. The low energy part of the SEY curve presents some specific features: a step just above the vacuum level as well as two bumps at 18 and $26 \mathrm{eV}$ are clearly visible. Some of these structures can be related to the band structure and plasmon energy of
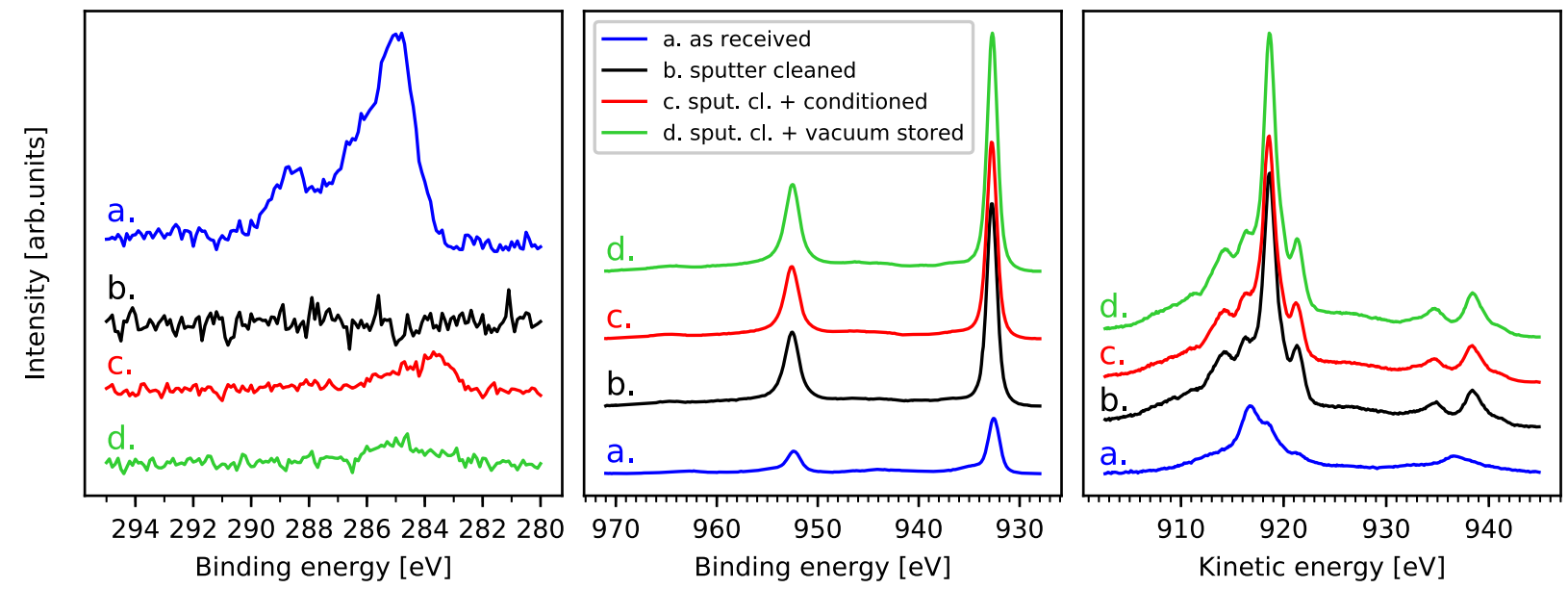

FIG. 4. $\mathrm{C} 1 \mathrm{~s}$ (left), $\mathrm{Cu} 2 \mathrm{p}$ (center) and $\mathrm{Cu}$ LMM (right) lines of a sputter-cleaned sample, before and after conditioning, and of a sputter-cleaned sample stored under vacuum. The as received state of the sputter-cleaned sample is shown for comparison.
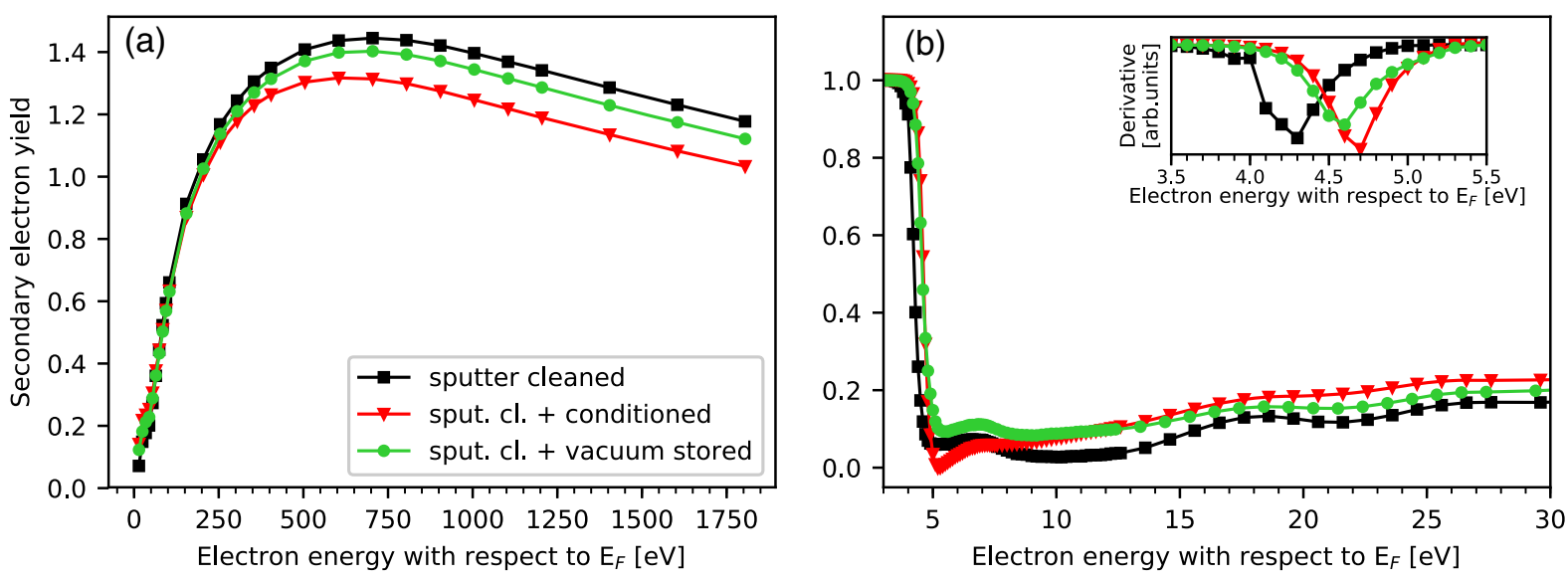

FIG. 5. (a) SEY curves from 10 to $1800 \mathrm{eV}$ of a sputter-cleaned sample, before and after conditioning, and of a sputter-cleaned sample stored under vacuum, (b) low energy SEY curves, inset: derivative of the SEY curves in the vacuum level region. 
copper $[38,39]$ and are not discussed further here. After a conditioning dose of $10^{-2} \mathrm{C} / \mathrm{mm}^{2}$, carbon and oxygen were detected to an amount of 1.6 and 0.6 at. \% respectively (Table I). These contaminants can be related to the flood gun along the arguments presented in the following. Indeed, the total pressure in the chamber increases up to $1.5 \times 10^{-9} \mathrm{mbar}$ when the flood gun is powered. Meanwhile, an increase of the peaks at $\mathrm{m} / \mathrm{q}=16\left(\mathrm{CH}_{4}\right)$, and $\mathrm{m} / \mathrm{q}=44\left(\mathrm{CO}_{2}\right)$ is observed in the residual gas analyzer spectrum. The intensity of these peaks remains at least one order of magnitude below the dominant one at $\mathrm{m} / \mathrm{q}=2\left(\mathrm{H}_{2}\right)$. Even though the signal to noise ratio of the $\mathrm{C} 1 \mathrm{~s}$ peak is low, a clear shift to lower binding energy is distinguished in Fig. 4 (curves $\mathrm{c}$ and a), with respect to the carbon present at the as received state of the sample. No modification is observed neither on the $\mathrm{Cu} 2 \mathrm{p}_{3 / 2}$ nor the $\mathrm{Cu}$ LMM Auger lines after irradiation.

The variation of the secondary electron yield during conditioning is not the same at all primary energies. While a slight decrease is observed above $\mathrm{E}_{p}=70 \mathrm{eV}$, with $\delta_{\max }$ going down to 1.32 at $\mathrm{E}_{\max }=600 \mathrm{eV}$, the yield between 7 and $70 \mathrm{eV}$ is increased by electron irradiation. The bumps present at 18 and $26 \mathrm{eV}$ above Fermi level after sputtering are barely visible, and the reflectivity just above the vacuum level reaches almost zero. The work function is increased up to $4.7 \mathrm{eV}$.

For comparison, a witness as received copper sample was fully sputter cleaned and stored in the analysis chamber for the same duration as the usual conditioning time. During the storage, the flood gun was powered, but not directly shooting onto the sample. A comparable amount of carbon and oxygen was observed at the surface after this vacuum storage procedure (1.1 and 0.2 at. \% respectively, see Table I). However, without directly irradiating the sample, the $\mathrm{C} 1 \mathrm{~s}$ line lies at the same position as the as received state of the sample, as shown in Fig. 4. The SEY after vacuum storage was found to be $\delta_{\max }=1.40$ at $\mathrm{E}_{\max }=700 \mathrm{eV}$ (Fig. 5). In addition, the features observed on the low energy part of the SEY curve after sputtering remain visible.

\section{Oxidized samples}

As observed above, the air-exposed copper surface contains a layer of oxide and airborne adsorbates. In order to disentangle the role of cuprous oxide and hydrocarbon contamination in the SEY decrease during electron irradiation, carbon-free oxidized copper samples were produced and conditioned. A load lock sample was obtained by venting a sputter-cleaned sample in 1 bar of a $\mathrm{O}_{2}$ and $\mathrm{N}_{2}$ mixture in the load lock for $45 \mathrm{~min}$. The "thick oxide" sample was prepared by heating an as received (detergent cleaned) sample for $270 \mathrm{~h}$ at $120^{\circ} \mathrm{C}$ in air, followed by in situ $\mathrm{Ar}^{+}$sputtering to obtain a clean cuprous oxide surface, free of contaminant.

The $\mathrm{Cu}$ LMM Auger lines for the two different kinds of oxidized samples are shown in Fig. 6. For the load lock sample the metallic copper peak at $\mathrm{E}_{k}=918.6 \mathrm{eV}$ is still the main contribution, while for the thick oxide sample the main component is at $\mathrm{E}_{k}=916.6 \mathrm{eV}$ (compatible with $\mathrm{Cu}_{2} \mathrm{O}$ [33]), the bulk copper component not being visible anymore. After oxidation, the load lock sample exhibits traces of carbon $(0.5$ at. \%) which are attributed to initial impurities in the oxidation gas bottle or contamination of the gas by the injection line. Traces of silicon up to 0.8 at. $\%$, probably resulting from the detergent cleaning process, were found on the surface of the thick oxide sample.

The SEY curves for the two kinds of oxidized samples are shown in Fig. 7 together with the curves of sputtercleaned sample, as a reference. Above $12 \mathrm{eV}$ of landing energy, the SEY of the two oxidized samples is identical. Oxidation is responsible for a global decrease of the SEY
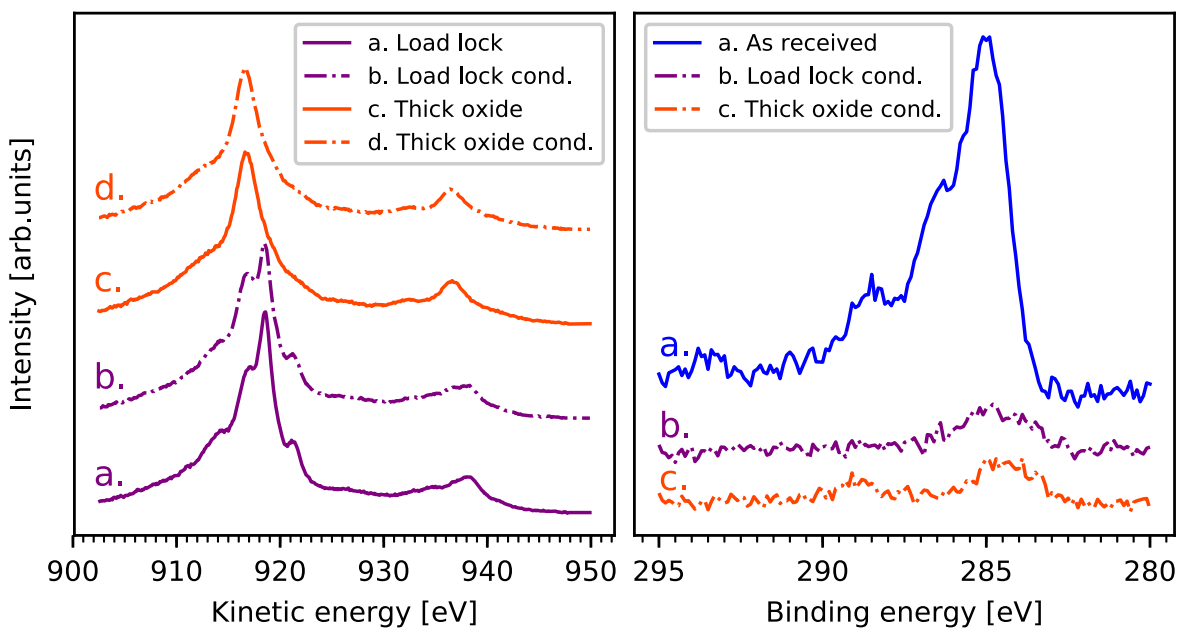

FIG. 6. (left) $\mathrm{Cu}$ LMM Auger lines of load lock and thick oxide samples, before and after conditioning, (right) $\mathrm{C}$ 1s lines of conditioned states for load lock and thick oxide samples. The $\mathrm{C} 1 \mathrm{~s}$ line of the as received state of the load lock sample is given as a reference. 

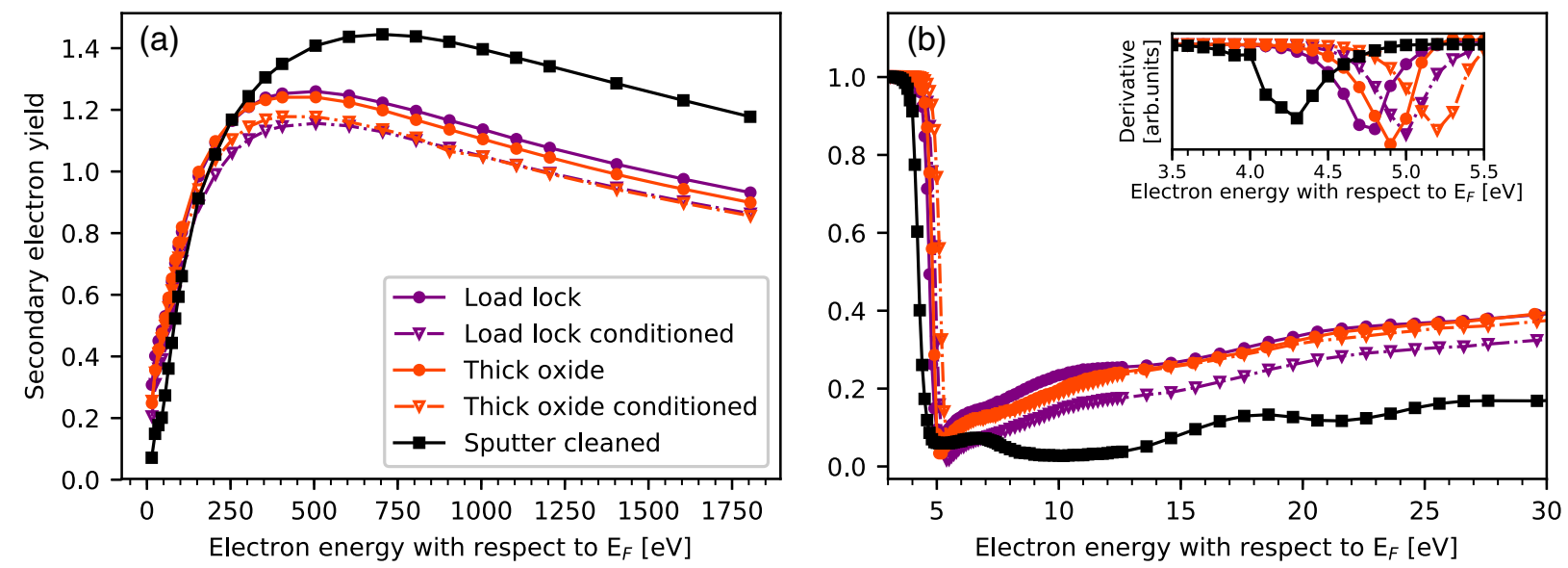

FIG. 7. (a) SEY curves from 10 to $1800 \mathrm{eV}$ of a load lock and thick oxide samples, before and after conditioning, (b) low energy SEY curves, inset: derivative of the SEY curves in the vacuum level region. The sputter-cleaned state is given for comparison.

above $250 \mathrm{eV}$ with respect to the sputter-cleaned state. The maximum SEY, 1.26 and 1.25 for load lock and thick oxide samples respectively, is found at $\mathrm{E}_{\max }=500 \mathrm{eV}$. These values are in good agreement with previous studies [40]. For primary energies lower than $250 \mathrm{eV}$, the yield is increased by the oxidation process with respect to sputtercleaned copper. Below $30 \mathrm{eV}$ and for both oxidized samples, no structures are visible at 18 and $26 \mathrm{eV}$. For both oxides, the work function is very similar: $\phi=$ 4.8-4.9 eV and higher than for the clean copper surface.

After conditioning of the load lock sample, 1.7 at. \% of carbon was detected on the sample surface, as for the conditioning of the sputter-cleaned copper sample (Table I). The oxygen amount slightly decreased down to 7.2 at. \%. For the thick oxide sample, 2.0 at. \% of carbon was found after conditioning and oxygen content remained constant. The $\mathrm{Cu}$ LMM Auger line of the load lock sample, shown in Fig. 6 (left), is slightly modified during conditioning: the ratio $\mathrm{Cu}_{2} \mathrm{O} / \mathrm{Cu}$ components is slightly increased. Figure 6 (right) shows the $\mathrm{C} 1 \mathrm{~s}$ lines of the load lock and thick oxide samples, after full conditioning, as well as the as received $\mathrm{C} 1 \mathrm{~s}$ line of the load lock sample, as a reference. For both the load lock and the thick oxide samples, the conditioning induces a clear shift of the $\mathrm{C} 1 \mathrm{~s}$ line with respect to airborne carbon contamination present at the as received state. No modification is observed for the other element lines.

The SEY of both oxidized samples decreases at high primary energies during conditioning. $\delta_{\max }$ yields at 1.16 and 1.18 for load lock and thick oxide samples respectively, at $\mathrm{E}_{\max }=400-500 \mathrm{eV}$. For the load lock sample, the yield at low energies also decreases, the shape of the SEY curve remaining the same. However, for the thick oxide sample, in the low energy region, the SEY curves before and after conditioning are overlapping. For both samples, the work function increased during irradiation to reach $5.0-5.2 \mathrm{eV}$.

\section{DISCUSSION}

\section{A. Influence of the surface components on the secondary electron yield}

The secondary electron yield of as received (air exposed) copper strongly decreases within the entire considered energy range during electron irradiation. In this study, the maximum SEY $\delta_{\max }$ decreases from 2.00 to $1.07, \mathrm{E}_{\max }$ remaining constant around 300-350 eV. XPS analysis reveals different surface modifications including removal of the $\mathrm{Cu}(\mathrm{OH})_{2}$ surface layer and carboxyl adsorbates. Hydroxide as well as adsorbed hydrocarbons are known to increase the yield of cleaned surfaces [41-43]. Part of the SEY reduction observed during irradiation can thus be attributed to the electron stimulated desorption or conversion of these species. In addition, since a slight carbon surface concentration decrease was observed during irradiation, the further $\delta_{\max }$ decrease cannot be attributed to any growth of a carbon layer on the sample surface, contrary to the conclusions drawn in [24].

The conditioning of a sputter-cleaned copper sample results in a $\delta_{\max }$ decrease from 1.44 to 1.32 , while $\mathrm{E}_{\max }$ shifts from 700 to $600 \mathrm{eV}$. Only a small amount of carbon is observed on the surface after conditioning and the $\mathrm{C} 1 \mathrm{~s}$ line position indicates that this carbon is more graphitic than the airborne carbon contamination [37]. A sputter-cleaned copper sample stored in the same vacuum conditions and for the same duration as for a conditioning experiment experienced a slight yield decrease and no $\mathrm{E}_{\max }$ shift. Its surface shows traces of carbon almost at the same level as for the irradiated sputter-cleaned sample, but without shift of the $\mathrm{C} 1 \mathrm{~s}$ line with respect to the as received state. In this case, the slight decrease of SEY can only be tentatively ascribed to the coverage of adsorbates on the surface. As a consequence of the minor $\delta_{\max }$ change and the slightly different amount of adsorbates, the main conclusion we can draw is that even on a pure metallic copper surface, carbon graphitization occurs only under direct electron irradiation. 
Since no other surface modification is observed for these two samples, the larger $\delta_{\max }$ and $\mathrm{E}_{\max }$ decrease observed for the sputter-cleaned sample during conditioning with respect to the vacuum stored sample could be attributed to the appearance of graphitic carbon. The ultimate $\delta_{\max }$ of the cleaned sample after conditioning remains still much higher than the one obtained for the conditioning of an air exposed sample. We conclude that the decrease of $\delta_{\max }$ down to the value observed for a conditioned air exposed sample requires either copper oxide and/or modification of adsorbed hydrocarbons to graphitic carbon. For the sputtercleaned surface, in the low energy part of the curve (below $70 \mathrm{eV}$ ), the SEY is increased by both the conditioning process and the vacuum storage. This opposite trend in the SEY variation upon surface modification depending on primary energy was already observed [16] and was attributed to enhanced surface scattering of low energy incident electrons due to adsorbed molecules.

The effect of copper surface oxidation on the SEY is independent of the oxide thickness in the investigated range. The maximum SEY of the load lock and thick $\mathrm{Cu}_{2} \mathrm{O}$ oxide samples is 1.26 and 1.25 , respectively, and occurs at $\mathrm{E}_{\max }=500 \mathrm{eV}$. These values are in good agreement with previous studies [40]. Since the thickness of the load lock sample is very low compared to the scale of the copper surface roughness, the roughness is not expected to increase significantly during this oxidation process. Furthermore, the geometric configuration (aspect ratio and spacing) of the cubic structures observed on the surface of the load lock oxide will not influence the SEY of the sample [44]. Thus, the lower maximum SEY of the load lock oxide with respect to the sputter-cleaned sample is unambiguously ascribed to the chemical modification of the surface. From Fig. 1, the thick oxide sample appears rougher and more porous than the load lock oxide. In addition, its oxide layer is more than 25 times thicker. Both the thicker oxide layer and the rougher surface would tend to decrease the SEY of the thick oxide sample below the one of the load lock sample. However, both samples exhibit the same maximum SEY at the same incident energy. It is thus concluded that the maximum SEY measured on the thick oxide sample is not influenced by its apparently rougher surface, and that the maximum SEY of the surface does not depend on the oxide thickness above $2 \mathrm{~nm}$ (equivalent $\mathrm{Ta}_{2} \mathrm{O}_{5}$ ). The oxidation process increases the yield and strongly modifies the SEY curve shape below $250 \mathrm{eV}$. The two oxide types exhibit equivalent SEY curves on the considered energy range. Full conditioning of oxidized samples reduces their yield down to $\delta_{\max }=$ 1.16 and 1.18 for load lock and thick oxide sample, respectively. For both samples, this decrease can be attributed, as for the conditioning of sputter-cleaned sample, to the small amount of graphitic carbon observed on the surface after conditioning. In all cases, the ultimate $\delta_{\max }$ reached at the end of the conditioning remains higher than the one measured on a fully conditioned air-exposed copper sample. Therefore, the formation of graphitic carbon appears to be necessary to decrease $\delta_{\max }$ down to the ultimate value observed on an as received sample.

The experiments show that oxidation decreases $E_{\max }$ with respect to sputter-cleaned copper (Table I). However, for the as received sample, after conditioning, $\mathrm{E}_{\max }$ is even lower, at 300-350 eV. This low value cannot be explained by the oxide layer, which is in the thickness range between the load lock and the thick oxide samples, both giving higher $\mathrm{E}_{\max }$. Therefore, carbon seems to be also responsible for the low value of $E_{\max }$ observed on the as received sample. Indeed, thin films of graphitic-like carbon show an $\mathrm{E}_{\max }$ around $300 \mathrm{eV}$ [12].

\section{B. Work function}

In common phenomenological models of generation of secondary electrons, both the surface barrier (work function) and the density of states play a role. It is generally expected that an increase of work function results in a decrease of the maximum SEY. In the following, we verify whether the decrease of SEY observed during conditioning and oxidation can be explained exclusively by a modification of work function.

For both sputter-cleaned and oxidized surfaces, the work function was found to increase during electron irradiation while the maximum SEY decreases. Therefore, during conditioning, the evolution of the two quantities is consistent with the expectations.

The work function of load lock sample increases from 4.3 to $4.8 \mathrm{eV}$ during oxidation and the one of thick oxide is found at $4.9 \mathrm{eV}$. Such an increase during oxidation is coherent with previous studies [45]. The lower $\delta_{\max }$ of oxidized samples with respect to sputter-cleaned copper could thus be explained by the work function increase. However, since previous studies showed that the work function increase occurs in the first oxidation steps [45], while the SEY decrease is rather pronounced for higher oxidation times [41], the lower maximum SEY observed after oxidation cannot be only ascribed to the work function increase.

In the case of as received copper, conditioning leads to the decrease of the SEY to the lowest measured value, but the work function remains unchanged (variation of $+0.1 \mathrm{eV}$, considered as the accuracy of the applied work function measurement method). This shows that the decrease of SEY cannot be explained only by the increase of work function and the contribution of the change in electronic density of states cannot be disentangled.

The most striking illustration of the fact that the work function alone cannot explain the complex behavior of the SEY is visible in the comparison of the as received sample with both kinds of oxidized samples, before conditioning, where the work function is identical while the maximum SEY displays a large difference. 


\section{CONCLUSIONS}

The role of the surface components in the conditioning process of copper was disentangled by studying three copper model surfaces: air exposed, sputter-cleaned, and carbon-free oxidized $\left(\mathrm{Cu}_{2} \mathrm{O}\right)$ copper. It is shown that none of the tested carbon-free surfaces conditions down to an ultimate $\delta_{\max }$ as low as the one obtained after the conditioning of an air-exposed copper sample.

Cuprous oxide $\mathrm{Cu}_{2} \mathrm{O}$ is found to have a passive role in reducing the maximum electron yield of a pure bulk copper: $\mathrm{Cu}_{2} \mathrm{O}$ has a lower $\delta_{\max }$ than $\mathrm{Cu}$, but no significant SEY decrease driven by oxide modification during irradiation is observed.

Carbon has an active role in reducing the maximum electron yield. Surface carbon amount of an air-exposed copper surface was found to slightly decrease during irradiation. Therefore, it is concluded that an increase of carbon coverage is not necessary to reduce the secondary electron yield to values close to 1 . It is shown that it is the modification of the airborne carbon into a more graphitic form during electron irradiation at $250 \mathrm{eV}$ that allows reducing the maximum electron yield of an air-exposed copper surface down to values lower than for pure copper or $\mathrm{Cu}_{2} \mathrm{O}$. More studies are ongoing to investigate a possible influence of the level of carbon contamination on the ultimate SEY after conditioning.

\section{ACKNOWLEDGMENTS}

The authors would like to thank A. Bellissimo for sharing her knowledge about low energy SEY measurements, D. A. Zanin and M. Himmerlich for the useful discussions and help along this study and A. T. Pérez Fontenla for the SEM observations. The help of R. Cimino in setting up the system for low energy SEY measurements is kindly acknowledged.

[1] G. Rumolo, F. Ruggiero, and F. Zimmermann, Simulation of the electron-cloud buildup and its consequences on heat load, beam stability, and diagnostics, Phys. Rev. ST Accel. Beams 4, 012801 (2001).

[2] O. Gröbner, in Proceedings of the 10th International Conference on High-Energy Accelerators, Protvino, Russia, 1977 (Institute of High Energy Physics, Serpukhov, 1977), p. 277.

[3] C. Yin Vallgren, G. Bregliozzi, and P. Chiggiato, in Proceedings of the 7th International Particle Accelerator Conference: IPAC 2016, Busan, Korea, 2016 (JACoW, Geneva, 2016), p. 3673.

[4] P. Costa Pinto, S. Calatroni, P. Chiggiato, P. Edwards, M. Mensi, H. Neupert, M. Taborelli, and C. Yin Vallgren, in ECLOUD'12, La Biodola, Italy, 2012 (CERN, Geneva, 2013), p. 141.

[5] L. Rossi and O. Brüning, The High Luminosity Large Hadron Collider: The New Machine for Illuminating the
Mysteries of the Universe (World Scientific, Hackensack, NJ, 2015).

[6] G. Iadarola, H. Bartosik, K. Li, L. Mether, A. Romano, G. Rumolo, and M. Schenk, in Proceedings of the 6th Evian Workshop on LHC Beam Operation, Evian-les-Bains, France, 2015 (CERN, Geneva, 2015), p. 101.

[7] G. Iadarola, L. Mether, and G. Rumolo, in Proceedings of the 7th Evian Workshop on LHC Beam Operation, Evianles-Bains, France, 2016 (CERN, Geneva, 2016), p. 239.

[8] G. Rumolo, in Proceedings of the 61st ICFA ABDW on High-Intensity and High-Brightness Hadron Beams, Daejeon, Korea, 2018 (JACoW, Geneva,2018), p. 8.

[9] S. Calatroni, E. Garcia-Tabares Valdivieso, H. Neupert, V. Nistor, A. T. Perez Fontenla, M. Taborelli, P. Chiggiato, O. Malyshev, R. Valizadeh, S. Wackerow, S. A. Zolotovskaya, W. A. Gillespie, and A. Abdolvand, First accelerator test of vacuum components with laser-engineered surfaces for electron-cloud mitigation, Phys. Rev. Accel. Beams 20, 113201 (2017).

[10] H. Fukuma, J. Flanagan, K. Hosoyama, T. Ieiri, T. Kawamoto, T. Kubo, M. Suetake, S. Uno, S. S. Win, and M. Yoshioka, Status of solenoid system to suppress the electron cloud effects at the KEKB, AIP Conf. Proc. 642, 357 (2002).

[11] Y. Suetsugu, H. Fukuma, L. Wang, M. Pivi, A. Morishige, Y. Suzuki, M. Tsukamoto, and M. Tsuchiya, Demonstration of electron clearing effect by means of a clearing electrode in high-intensity positron ring, Nucl. Instrum. Methods Phys. Res., Sect. A 598, 372 (2009).

[12] C. Yin Vallgren, G. Arduini, J. Bauche, S. Calatroni, P. Chiggiato, K. Cornelis, P. Costa Pinto, B. Henrist, E. Métral, H. Neupert, G. Rumolo, E. Shaposhnikova, and M. Taborelli, Amorphous carbon coatings for the mitigation of electron cloud in the CERN Super Proton Synchrotron, Phys. Rev. ST Accel. Beams 14, 071001 (2011).

[13] O. Brüning, P. Collier, P. Lebrun, S. Myers, R. Ostojic, J. Poole, and P. Proudlock, LHC Design Report (CERN, Geneva, 2004).

[14] Y. Suetsugu, K. Kanazawa, K. Shibata, T. Ishibashi, H. Hisamatsu, M. Shirai, and S. Terui, Design and construction of the SuperKEKB vacuum system, J. Vac. Sci. Technol. A 30, 031602 (2012).

[15] Y. Suetsugu, K. Shibata, T. Ishibashi, H. Fukuma, M. Tobiyama, J. Flanagan, E. Mulyani, M. Shirai, S. Terui, K. Kanazawa, and H. Hisamatsu, Achievements and problems in the first commissioning of superKEKB vacuum system, J. Vac. Sci. Technol. A 35, $03 E 103$ (2017).

[16] L. A. Gonzalez, M. Angelucci, R. Larciprete, and R. Cimino, The secondary electron yield of noble metal surfaces, AIP Adv. 7, 115203 (2017).

[17] R. Larciprete, D. R. Grosso, M. Commisso, R. Flammini, and R. Cimino, Secondary electron yield of $\mathrm{Cu}$ technical surfaces: Dependence on electron irradiation, Phys. Rev. ST Accel. Beams 16, 011002 (2013).

[18] R. Cimino, M. Commisso, D. R. Grosso, T. Demma, V. Baglin, R. Flammini, and R. Larciprete, Nature of the Decrease of the Secondary-Electron Yield by Electron Bombardment and its Energy Dependence, Phys. Rev. Lett. 109, 064801 (2012). 
[19] T. L. Barr, An ESCA study of the termination of the passivation of elemental metals, J. Phys. Chem. 82, 1801 (1978).

[20] S. K. Chawla, B. I. Rickett, N. Sankarraman, and J. H. Payer, An X-ray photoelectron spectroscopic investigation of the air-formed film on copper, Corros. Sci. 33, 1617 (1992).

[21] B. Henrist, N. Hilleret, C. Scheuerlein, M. Taborelli, and G. Vorlaufer, in Proceedings of the 8th European Particle Conference: EPAC 2002, Paris, France, 2002 (European Physical Society, Geneva, 2002), p. 2553.

[22] M. Nishiwaki and S. Kato, Electron stimulated gas desorption from copper material and its surface analysis, Appl. Surf. Sci. 169-170, 700 (2001).

[23] M. Nishiwaki and S. Kato, Graphitization of inner surface of copper beam duct of KEKB positron ring, Vacuum $\mathbf{8 4}$, 743 (2009).

[24] C. Scheuerlein, M. Taborelli, N. Hilleret, A. Brown, and M. A. Baker, An AES study of the room temperature conditioning of technological metal surfaces by electron irradiation, Appl. Surf. Sci. 202, 57 (2002).

[25] C. Scheuerlein and M. Taborelli, Electron stimulated carbon adsorption in ultrahigh vacuum monitored by Auger electron spectroscopy, J. Vac. Sci. Technol. A 20, 93 (2002).

[26] R. Cimino, L. A. Gonzalez, R. Larciprete, A. Di Gaspare, G. Iadarola, and G. Rumolo, Detailed investigation of the low energy secondary electron yield of technical $\mathrm{Cu}$ and its relevance for the LHC, Phys. Rev. ST Accel. Beams 18, 051002 (2015).

[27] G. Rovida, F. Pratesi, M. Maglietta, and E. Ferroni, Chemisorption of oxygen on the silver (111) surface, Surf. Sci. 43, 230 (1974).

[28] H. Kawano, Effective work functions for ionic and electronic emissions from mono- and polycrystalline surfaces, Prog. Surf. Sci. 83, 1 (2008)

[29] G. Panzner, B. Egert, and H. P. Schmidt, The stability of $\mathrm{CuO}$ and $\mathrm{Cu}_{2} \mathrm{O}$ surfaces during argon sputtering studied by XPS and AES, Surf. Sci. 151, 400 (1985).

[30] U. R. Evans and H. A. Miley, Measurements of oxide films on copper and iron, Nature (London) 139, 283 (1937).

[31] T. N. Rhodin, Low temperature oxidation of copper. I. Physical mechanism, J. Am. Chem. Soc. 72, 5102 (1950).

[32] M. R. Pinnel, H. G. Tompkins, and D. E. Heath, Oxidation of copper in controlled clean air and standard laboratory air at $50{ }^{\circ} \mathrm{C}$ to $150{ }^{\circ} \mathrm{C}$, Appl. Surf. Sci. 2, 558 (1979).
[33] S. Poulston, P. M. Parlett, P. Stone, and M. Bowker, Surface oxidation and reduction of $\mathrm{CuO}$ and $\mathrm{Cu}_{2} \mathrm{O}$ studied using XPS and XAES, Surf. Interface Anal. 24, 811 (1996).

[34] N.S. Mclntyre and M. G. Cook, X-ray photoelectron studies on some oxides and hydroxides of cobalt, nickel, and copper, Anal. Chem. 47, 2208 (1975).

[35] T. Robert, M. Bartel, and G. Offergeld, Characterization of oxygen species adsorbed on copper and nickel oxides by x-ray photoelectron spectroscopy, Surf. Sci. 33, 123 (1972).

[36] J. F. Moulder, W. F. Stickle, P. E. Sobol, and K. D. Bomben, Handbook of X-Ray Photoelectron Spectroscopy: A Reference Book of Standard Spectra for Identification and Interpretation of XPS Data, Physical Electronics Division (Perkin-Elmer Corporation, Eden Prairie, 1995).

[37] J. Díaz, G. Paolicelli, S. Ferrer, and F. Comin, Separation of the sp3 and sp2 components in the $\mathrm{C} 1 \mathrm{~s}$ photoemission spectra of amorphous carbon films, Phys. Rev. B 54, 8064 (1996).

[38] H. Eckardt, L. Fritsche, and J. Noffke, Self-consistent relativistic band structure of the noble metals, J. Phys. F 14, 97 (1984).

[39] A. Siokou, F. Ravani, S. Karakalos, O. Frank, M. Kalbac, and C. Galiotis, Surface refinement and electronic properties of graphene layers grown on copper substrate: An XPS, UPS and EELS study, Appl. Surf. Sci. 257, 9785 (2011).

[40] H. Bruining and J. H. de Boer, Secondary electron emission part V. The mechanism of secondary electron emission, Physica (Amsterdam) 6, 834 (1939).

[41] I. Bojko, N. Hilleret, and C. Scheuerlein, Influence of air exposures and thermal treatments on the secondary electron yield of copper, J. Vac. Sci. Technol. A 18, 972 (2000).

[42] J. Halbritter, On changes of secondary emission by resonant tunneling via adsorbates, J. Phys. (Paris), Colloq. 45,C2-315 (1984).

[43] N. Hilleret, C. Scheuerlein, and M. Taborelli, The secondary-electron yield of air-exposed metal surfaces, Appl. Phys. A 76, 1085 (2003).

[44] M. Pivi, F. K. King, R. E. Kirby, T. O. Raubenheimer, G. Stupakov, and F. Le Pimpec, Sharp reduction of the secondary electron emission yield from grooved surfaces, J. Appl. Phys. 104, 104904 (2008).

[45] L. F. Wagner and W. E. Spicer, Photemission study of the oxidation of copper films, Surf. Sci. 46, 301 (1974). 